\title{
Wind Turbine and Photovoltaic Hybrid Generations under Extreme Operating Gust
}

\author{
Ahmad Eid ${ }^{*}$ and Mamdouh Abdel-Akher
}

Electrical Engineering Department, Aswan University, Aswan 8154, Egypt

\begin{abstract}
A micro-grid consisting of a $300 \mathrm{~kW}$ wind turbine and a $40 \mathrm{~kW}$ photovoltaic array is investigated under extreme operating gust (EOG) wind scenarios. The micro-grid is connected to the $380-\mathrm{V}$ utility through a utility-side converter using natural-frame control, which provides a constant voltage of the DC link between the micro-grid and utility. The impact of the extreme gust wind variations on the micro-grid performance is studied for variable speed wind energy system equipped with a squirrel-cage induction generator. The Hurghada city, Red Sea, Egypt is taken as a case study for the wind speed profile. A detailed model of extreme gust-wind speed variation is implemented and simulated using PSIM commercial software package, based on climate characteristics of Hurghada city. The indirect rotor field oriented control (FOC) method is implemented to the generator-side converter to keep the system stable under the extreme gust wind conditions and to control the squirrel-cage induction generator (SCIG) speed for maximum power-point tracker (MPPT) regime. Power quality of the utility-side converter in terms of operation at different power factors, voltage value and THD are verified.
\end{abstract}

Keywords: Gust winds, induction generator, micro-grid, photovoltaic, wind turbine.

\section{INTRODUCTION}

The demands of energy around the world increase rapidly, and hence, the need for a renewable energy supply has been increased. These new energy sources will not harm the environment or human being. Studies indicate that the global energy demand will almost triple by 2050 [1]. Renewable energy sources currently supply about $15 \%$ to $20 \%$ of total world energy demand [2-4]. According [5], in 2009, it showed a growth rate of $31.7 \%$, reaching $159.2 \mathrm{GW}$ (38.3 GW were added in 2009) of worldwide power capacity and generated 340 TWh of electricity. PV and wind energy conversion systems are the most promising candidates for future energy technology. It is expected that about $30 \%$ contribution to world energy supply from renewable energy resources by year 2020 [1]. These supplies would reduce the energy related $\mathrm{CO}_{2}$ emissions by 25 $\%$ and hence reducing impacts of energy production and consumption on the surrounding environment and human health.

Hurghada wind energy has been operated since 1993; it includes wind turbines with different technologies and manufacturers. The percentage of local manufacturing in this plant reached about $40 \%$ (blades, towers, mechanical and electrical works) and the capacity of wind turbines ranges between 100 to $300 \mathrm{~kW}$. The total production of this plant in 2010/2011 reached about $7 \mathrm{GWh}$, saving about 1.5 thousand tons of oil equivalents and reducing the emission of about

*Address correspondence to this author at the Electrical Engineering Department, Aswan University, Aswan 81542, Egypt; Tel: +2097-466-1406; Fax: +2097-466-1406; E-mail: ahmadeid@aswu.edu.eg
4000 tons of carbon dioxide [6]. The strategy of New and Renewable Energy Authority of Egypt NREA, which was approved in February 2008, aims to the contribution of renewable energies by $20 \%$ of the total electricity generation by the year 2020 , including $12 \%$ contribution from wind energy, translating about 7200 MW grid-connected wind farms. The wind power mainly depends on geographic and weather conditions and varies from time-to-time. Therefore it is necessary to construct a system that can generate maximum power for all operating conditions.

The squirrel-cage induction generator (SCIG) has advantages like simplicity, low cost, rugged, high efficiency, maintenance-free, rigid and brushless. These advantages make the induction machine very attractive for wind power applications both for fixed and variable speed operation [7]. For variable wind and machine speeds, an efficient bidirectional PWM converter is required to capture as much energy as possible from the wind. The generator-side converter is controlled using the field-oriented control (FOC) [8]. It has the ability to control the frequency, amplitude and phase of the motor drive voltage.

In this paper, the robustness of the power electronics converter is validated under the extreme gust wind conditions and the converters are found to be robust against wind speed variations. It is worth to mention here that the pitch angle control is not applied here and the pitch angle is considered constant at zero value. The main purpose of this work is to emphasize on the capability of the adopted control methods to keep the micro-gird stable even in the extreme gust 
wind conditions as well as the power flow interaction between the micro-grid and utility.

\section{MODELING OF EXTREME OPERATING GUST WIND}

The extreme operating gust wind condition contains a peak gust and rapid changes in wind speed. The duration of these gusts lasts between $2 \mathrm{~s}$ up to 20s [9]. The mathematical model of the extreme gust wind depends on the climatic characteristics of the site. The EOG wind function is as follows [9-12]:

$$
\begin{aligned}
& v(z, t)=v_{r}-0.37 v_{g p}[\sin (3 \pi t / \tau)] \\
& {[1-\cos (2 \pi t / \tau)], \tau_{s} \leq t \leq \tau_{f}}
\end{aligned}
$$

where $v_{\mathrm{gp}}$ is the peak extreme gust magnitude and for a recurrence period of 1 year, it is given by:

$$
v_{g p}=4.8 \sigma /\left[1+0.1 D / a_{t}\right]
$$

where $D$ is the rotor diameter and $a_{t}$ is the turbulence scale parameter where it can be calculated from the hub height $\mathrm{H}_{\text {hub }}$ of less than $30 \mathrm{~m}$ as:

$a_{t}=0.7 H_{h u b}$

The parameter $\sigma$ is the standard deviation of longitudinal wind velocity and calculated from:

$$
\sigma=I_{15}\left(15+a v_{h u b}\right) /(a+1)
$$

where $I_{15}$ is the characteristic value of the turbulence at a 10 minutes wind speed of $15 \mathrm{~m} / \mathrm{s}$, and $a$ is the slope of the turbulence intensity. The wind turbine system classes are used to determine the suitable turbine for the normal wind conditions of a particular site [10,11]. The wind classes are mainly defined by the average annual wind speed that is measured at the turbine hub height, the speed of extreme gusts that could occur over $\mathrm{N}$ years, and how much turbulence there is at the wind site. The wind turbine system classes are defined by IEC 61400-1 correspond to high, medium and low wind speed as shown in Table 1. It shows that, there are four classes for wind turbine.

In this paper, these classes are used to choose a suitable wind turbine generator for climate characteristics of Hurghada site. Wind Atlas of Egypt concludes that the yearly average wind speed at Hurghada site is about $7.4 \mathrm{~m} / \mathrm{s}$ measured at a height above the ground of $25 \mathrm{~m}$. The NREA annual report, 2012, reported that the suggested capacity of each wind turbine generator is $100-300 \mathrm{~kW}$ [6]. One expression that is often used to characterize the impact of the roughness of the earth's surface on wind speed is the following [13]:

$$
v(z)=V_{r}\left(z / z_{r}\right)^{\alpha}
$$

where $v(z)$ is the average wind speed at height $z$ above the ground $(\mathrm{m} / \mathrm{s}), z_{r}$ is the reference height of the wind speed measurement $(25 \mathrm{~m})$, and $v_{\mathrm{r}}$ is the wind speed at $\mathrm{z}_{\mathrm{r}}$ averaged over ten minutes $(7.4 \mathrm{~m} / \mathrm{s}$ for Hurghada site).

The power law exponent $\alpha$ is assumed 0.25 , which is the standard value for the Egyptian terrain and wind conditions [10]. From (5) and for a tower height of $60 \mathrm{~m}$ above the ground, the rated wind speed at Hurghada site will be $9 \mathrm{~m} / \mathrm{s}$ and its wind class according to Tables 1 is $\mathbf{3}$. The maximum average wind speed at Hurghada city is $7.4 \mathrm{~m} / \mathrm{s}$ occurs in September with a minimum in October of $5.3 \mathrm{~m} / \mathrm{s}$. The specifications of the $300 \mathrm{~kW}$ wind turbine are listed in Table 2.

\section{WIND TURBINE AND GENERATOR CONTROLS}

\section{A. Wind Turbine Model}

The output power of the turbine $\mathrm{P}_{\mathrm{t}}$ is a nonlinear relationship with the wind speed and it is given by [13,

\begin{tabular}{|c|c|c|c|c|c|}
\hline \multirow{2}{*}{ Class } & \multirow{2}{*}{$V_{\text {hub }}(\mathrm{m} / \mathrm{s})$} & \multicolumn{2}{|c|}{ High Turbulence } & \multicolumn{2}{|c|}{ Low Turbulence } \\
\hline & & $I_{15}$ & $a$ & $I_{15}$ & $a$ \\
\hline I & 10 & \multirow{4}{*}{0.18} & \multirow{4}{*}{2} & \multirow{4}{*}{0.16} & \multirow{4}{*}{3} \\
\hline II & 8.5 & & & & \\
\hline III & 7.5 & & & & \\
\hline IV & 6 & & & & \\
\hline
\end{tabular}
15]:

$$
P_{t}=0.5 C_{P}(\lambda, \beta) \rho A v^{3}
$$

Table 1: Wind Turbine System Classes [10] 
Table 2: Wind Turbine Pecifications

\begin{tabular}{|c|c|c|c|}
\hline Parameter & Value & Parameter & Value \\
\hline \hline Rated power & $300 \mathrm{~kW}$ & Rotor speed & $46.875 \mathrm{rpm}$ \\
\hline Cut-in wind speed & $4.5 \mathrm{~m} / \mathrm{s}$ & Gear box ratio & $1: 32$ \\
\hline Rated wind speed & $12 \mathrm{~m} / \mathrm{s}$ & Generator speed & $1500 \mathrm{rpm}$ \\
\hline Cut-out wind speed & $25 \mathrm{~m} / \mathrm{s}$ & Grid frequency & $50 \mathrm{~Hz}$ \\
\hline Rotor diameter & $31 \mathrm{~m}$ & $\lambda_{\text {opt }}$ & 4.25 \\
\hline Number of blades & 3 & C $_{\text {pmax }}$ & $1 / 3$ \\
\hline
\end{tabular}

where $C_{p}$ is power coefficient, $\rho$ is air density, $A$ is swept area of rotor blades, $v$ is the wind speed, $\lambda$ is the tip speed ratio, and $\beta$ is the pitch angle. The power coefficient $C_{p}$ represents the ratio of the output mechanical power to the wind turbine power extracted from the wind. It is a function of the tip-speed ratio $\lambda$ and the blade pitch angle $\beta$. The angle $\beta$ is controlled by using a "pitch-controller" and $\lambda$ is given as:

$\lambda=\omega_{t} R / v$

where $\omega_{t}$ is the rotational speed of the wind turbine shaft and $R$ is the rotor blade radius. Hence, to get maximum power from the wind, $\lambda$ should be kept constant by controlling the generator rotational speed accordingly to the variations of the wind speed. This principle is called maximum-power point tracking (MPPT). Since the rotational speed of the wind turbine is much smaller than that of the induction generator, a gearbox must be inserted to connect their shafts. The gearbox (like a transformer) increases the speed and decreases the torque by the value of its ratio.

\section{B. Induction Generator Speed Control using FOC}

The advantage of the FOC is the decoupled control of the rotor flux and the electromagnetic torque of the SCIG to achieve a high dynamic performance. The rotor flux orientation is achieved by aligning the d-axis of the synchronous reference frame with the rotor flux vector as $[8,15]$ :

$\lambda_{d r}=\lambda_{r}, \quad \lambda_{q r}=0$ $T_{e m}$ is:

Then the electromagnetic torque of the generator,

$T_{e m}=\left(1.5 P L_{m} / L_{r}\right) \lambda_{r} i_{q s}=k_{t} \lambda_{r} i_{q s}$

where $k_{t}$ is the torque constant. If the rotor flux is kept constant, the torque can be controlled by $i_{q s}$.
The rotor flux angle $\theta_{f}$ required for conversion is given as:

$\theta_{f}=\int\left(\omega_{r}+\omega_{s l}\right) d t$

where $\omega_{\mathrm{r}}$ is the measured rotor speed and $\omega_{\mathrm{sl}}$ is the slip frequency and is calculated from rotor time constant $\tau_{\mathrm{r}}$ as:

$\omega_{s l}=\frac{L_{m}}{\tau_{r} \lambda_{r}} i_{q s}, \quad \tau_{r} \frac{L_{r}}{R_{r}}$

Then the rotor flux linkage can be expressed as:

$\lambda_{r} \frac{L_{m}}{\left(1+p \tau_{r}\right)} i_{d s}$

where $p$ is the differential operator.

From (12), when $i_{d s}$ is kept constant at its rated value, the rotor flux linkage $\lambda_{r}$ is constant, and hence, the electromagnetic torque is fully controlled by the qaxis current $i_{q s}$ as in (9). A complete diagram of the indirect FOC is shown in Figure 1. For MPPT operation of the WT, the wind speed $V_{w}$ and SCIG mechanical speed $\omega_{\mathrm{m}}$ used as input parameters as well as the generator three-phase currents. Using abc/dq0 conversion, the decoupled currents are obtained. The reference $d$-axis current is generated from a PI controller of the flux linkage difference. From the wind speed, SCIG rotor reference speed is obtained using MPPT block and by using a PID controller, the reference torque is generated. With the help of (9), the reference q-axis current is obtained. Using dq0/abc conversion, the reference three-phase stator currents are obtained. These currents are compared by the actual stator current and the PWM gate signals are generated using hysteresis band (HB) current control.

The utility-side converter control is shown in Figure 2 where $i_{d}-i_{q}$ current (natural frame) control is used to 


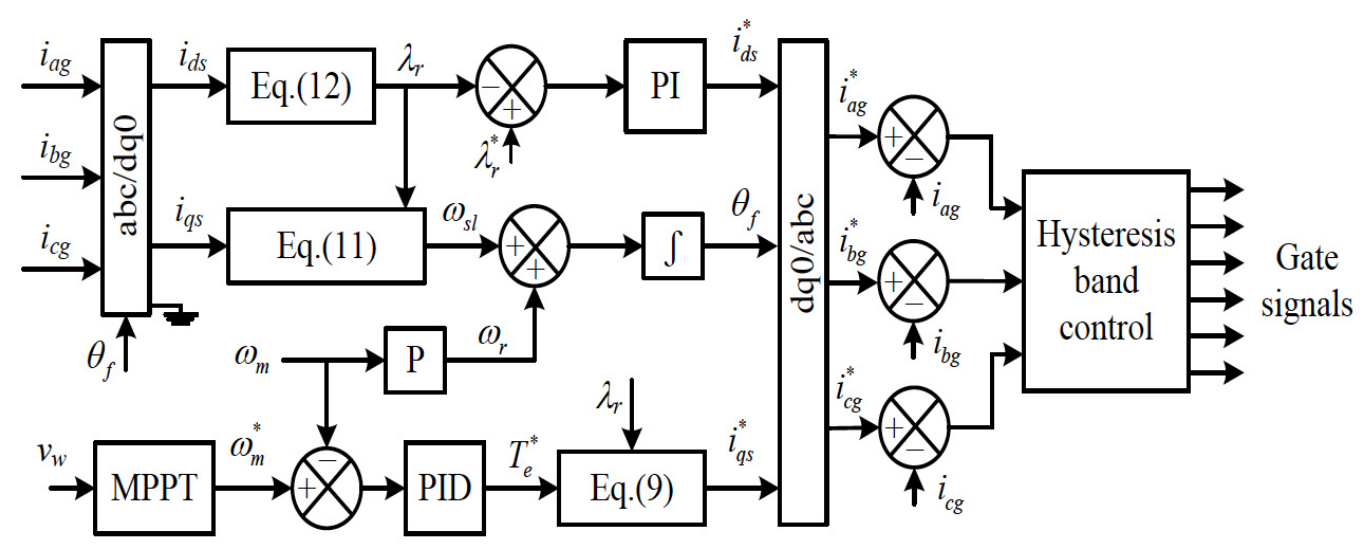

Figure 1: Indirect FOC control of the generator-side converter.

generate the corresponding reference currents separately. The d-axis reference current is obtained from the DC-bus voltage regulation using a PID controller. The q-axis reference current is obtained from the reference reactive power generated from the converter. This current component determines the required operation of the utility-side converter regarding the PF. If unity power factor is needed, simply let $Q_{r}$ equals to zero. If $Q_{r}$ is positive/negative, the PF will be lead/lag, respectively. Using dq0/abc conversion, the reference phase currents are generated and compared to the actual phase currents.

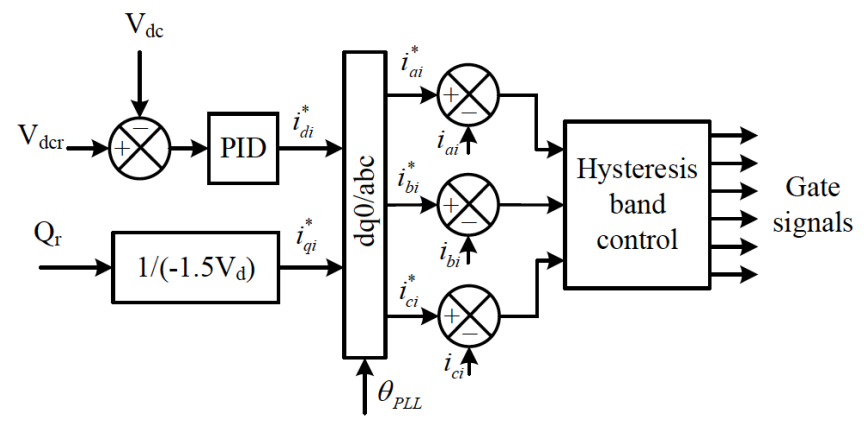

Figure 2: Utility-side converter control.

Then, a hysteresis band current controller generates the gate signals of the utility-side converter.

\section{MICRO-GRID SIMULATIONS}

The studied micro-grid consisting of a wind turbine energy conversion system and a photovoltaic module as shown in Figure 3, with their corresponding controls, is simulated in PSIM environment to verify the microgrid integration to utility and to check the performance of the micro-grid during transient and steady state conditions with wind gusts at different amplitudes. The pitch angle control is not applied here and the pitch angle is kept constant at zero value. The main purpose of study is to show the effectiveness of the adopted control methods to keep the micro-grid stable even with gust wind conditions. The rated wind speed is $12 \mathrm{~m} / \mathrm{s}$ while at Hurghada site, the average wind speed is about $9 \mathrm{~m} / \mathrm{s}$. The micro-grid is simulated at both wind speeds. Only three-phase load is connected at the PCC point. An LC filter is placed before the PCC to mitigate the harmonics generated from the high switching frequency of the utility-side converter.

The micro-grid shown in Figure 3 is simulated at the rated wind speed $12 \mathrm{~m} / \mathrm{s}$ and at Hurghada site average wind speed of $9 \mathrm{~m} / \mathrm{s}$ with the extreme gust superimposed on them as shown in Figure 4. The duration of the gust wind is $10 \mathrm{~s}$ and its peak is calculated from (1)-(4) with the help of the data of Table 1. The generator-side converter with the FOC regulates the rotational speed of the SCIG to follow the MPPT regime. The corresponding SCIG mechanical speed $\mathrm{N}_{\mathrm{g}}$ (in rpm) is shown in Figure $\mathbf{5}$ at the two wind speeds. The simulated gust wind starts at $3 \mathrm{~s}$ and end at $13 \mathrm{~s}$ with a period of $10 \mathrm{~s}$. In the regions outside the gust wind, the SCIG speed $\mathrm{N}_{\mathrm{g}}$ is regulated at $1512 \mathrm{rpm}$ slightly higher than its base speed of 1500 rpm, keeping the slip at $-0.8 \%$.

The utility-side converter, with the $\mathrm{i}_{\mathrm{d}}-\mathrm{i}_{\mathrm{q}}$ current control, regulates the $\mathrm{DC}$ bus voltage $\mathrm{V}_{\mathrm{dc}}$ as shown in Figure 6 with the corresponding current $I_{d c}$. As seen from Figure 7 , the $V_{d c}$ is constant even with the increase of the DC bus current $I_{d c}$ interacting with the increased power and speed of the generator during gust winds. The output powers of the SCIG $P_{g}$, and the utility $\mathrm{P}_{\mathrm{u}}$ are shown in Figure $\mathbf{7}$ corresponding to the gust wind scenarios at the two wind speeds of $12 \mathrm{~m} / \mathrm{s}$ and $9 \mathrm{~m} / \mathrm{s}$. The load power $P_{L}$ is kept constant at $400 \mathrm{~kW}$ and the PV at its rated power of $40 \mathrm{~kW}$ using $1 \mathrm{~kW} / \mathrm{m}^{2}$ for solar insolation and $25^{\circ} \mathrm{C}$ for a temperature. The output power of the generator $\mathrm{P}_{\mathrm{g}}$ follows the profile 


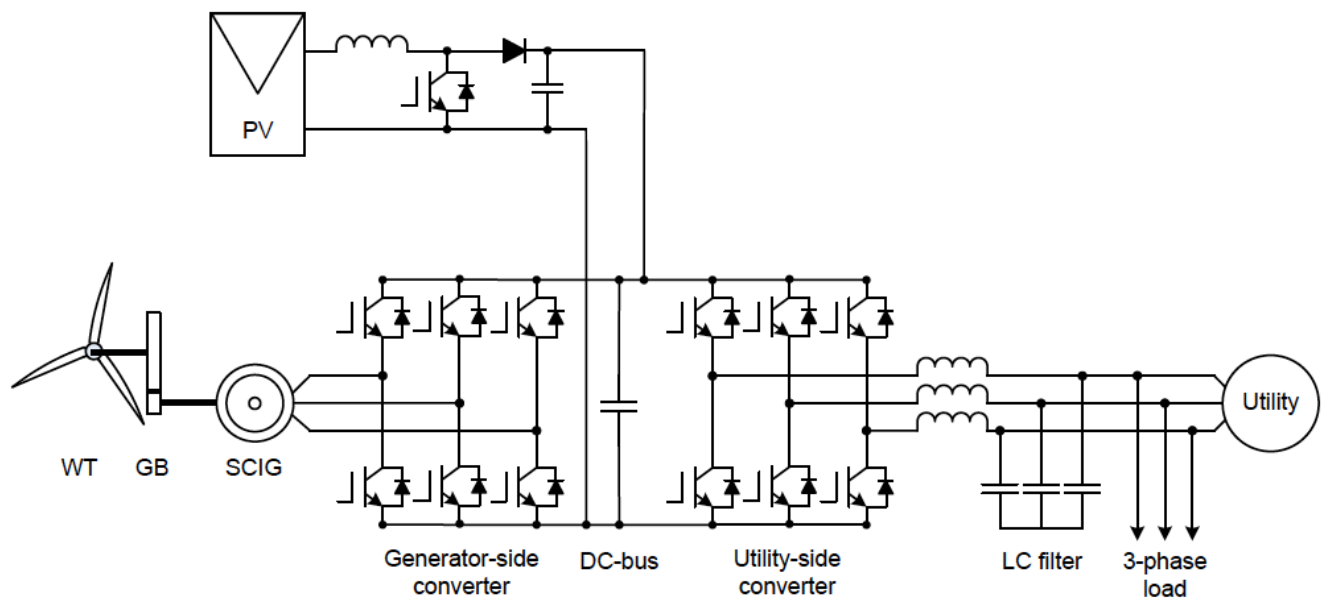

Figure 3: Micro-grid configuration connected to the utility.

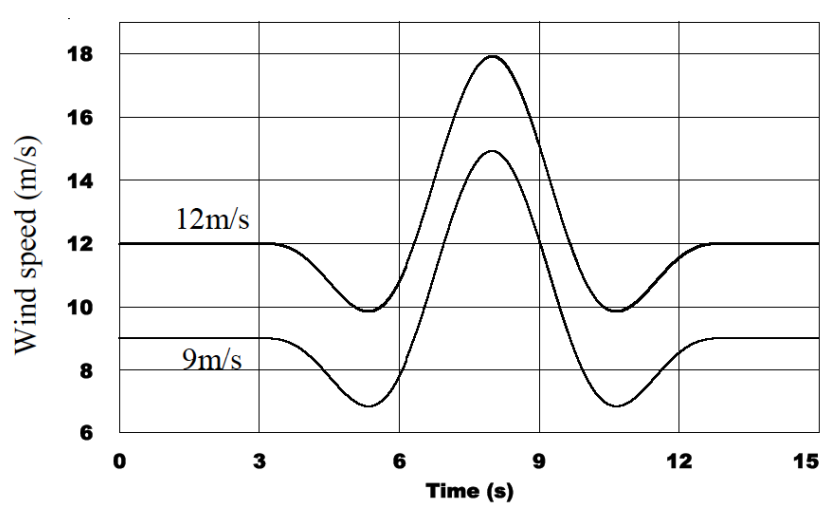

Figure 4: Wind speeds with EOG at pre-gust speeds of $12 \mathrm{~m} / \mathrm{s}$ and $9 \mathrm{~m} / \mathrm{s}$.

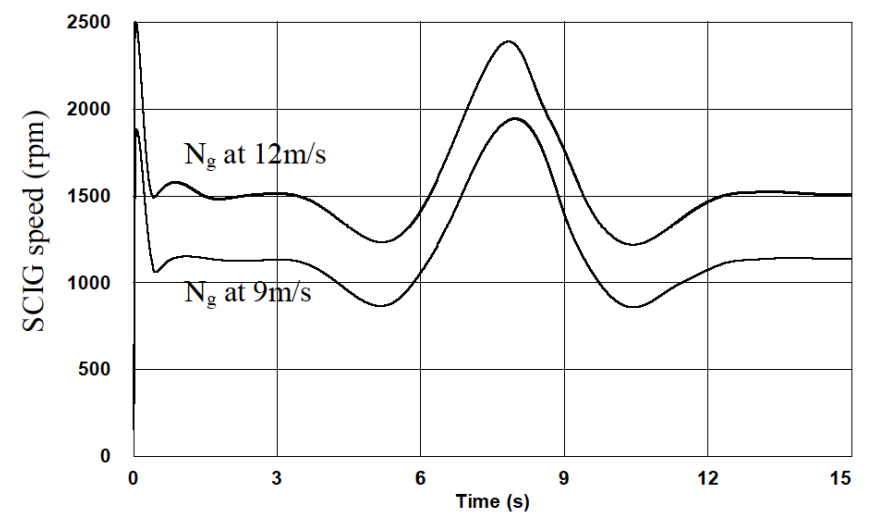

Figure 5: The SCIG mechanical speed with EOG at pre-gust speeds of $12 \mathrm{~m} / \mathrm{s}$ and $9 \mathrm{~m} / \mathrm{s}$.

of the wind speed, and hence, with decreasing or increasing the wind speed, the $P_{g}$ decreases and increases, respectively.

At any time, the power extracted from the micro-grid are supplied to the three-phase load and if there is an excess of power, it will be sent to the utility and it appears as a negative value in Figure 7 for $P_{u}$. Hence:

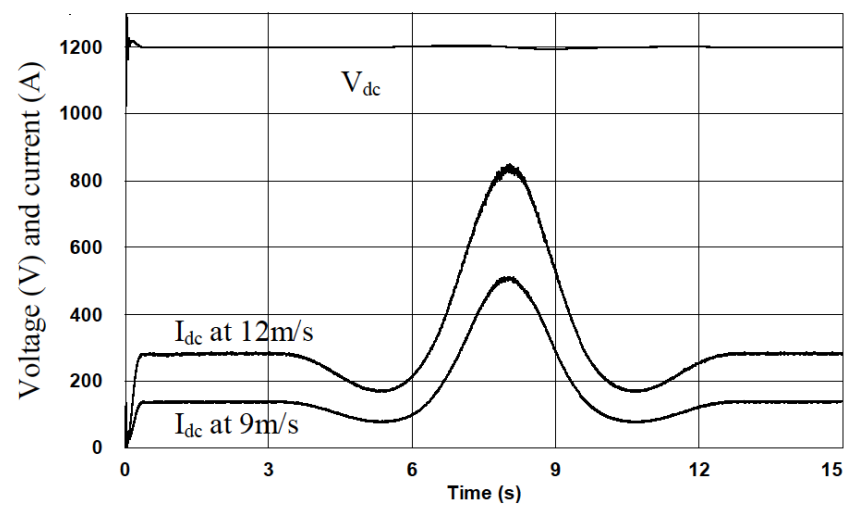

Figure 6: The $\mathrm{DC}$ bus voltage $\mathrm{V}_{\mathrm{dc}}$ and current $\mathrm{I}_{\mathrm{dc}}$ at pre-gust speeds of $12 \mathrm{~m} / \mathrm{s}$ and $9 \mathrm{~m} / \mathrm{s}$.

$P_{u}=P_{P V}+P_{g}-P_{L}$

The three-phase currents of the SCIG at the two speeds of $12 \mathrm{~m} / \mathrm{s}$ and $9 \mathrm{~m} / \mathrm{s}$ are shown in Figure 8 . It is clear that the FOC with the hysteresis band current controls make the current waves free of harmonics.

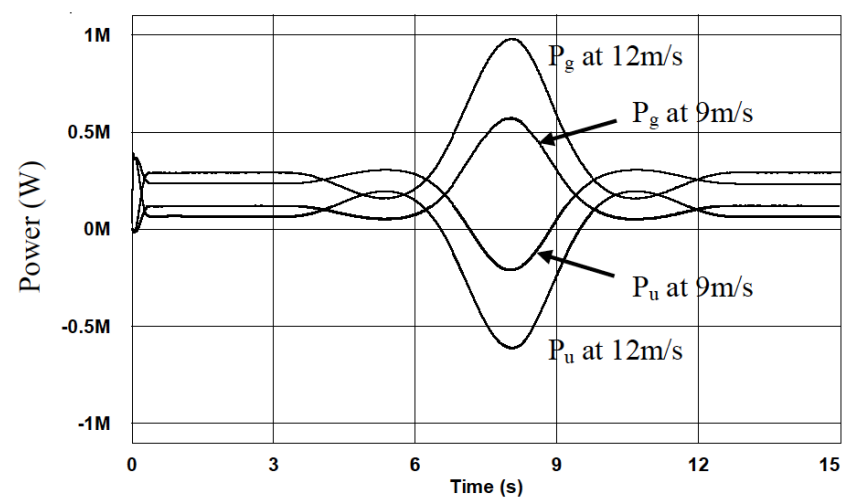

Figure 7: Output powers of generator $\mathrm{P}_{\mathrm{g}}$ and utility $\mathrm{P}_{\mathrm{u}}$ at wind bases of $12 \mathrm{~m} / \mathrm{s}$ and $9 \mathrm{~m} / \mathrm{s}$.

The utility-side converter also responsible for controlling the amount of the reactive power sent to the 

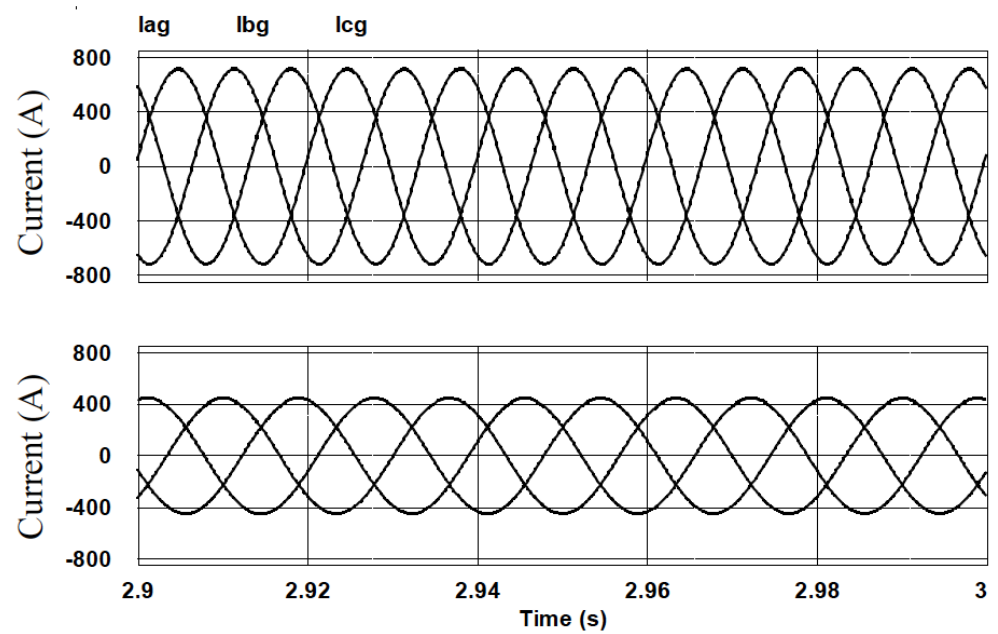

Figure 8: SCIG three-phase currents at $12 \mathrm{~m} / \mathrm{s}$ (top) and $9 \mathrm{~m} / \mathrm{s}$ (bottom).

utility by regulating the $i_{q}$ current as shown in Figure 2 . The voltage $V_{d}$ is the direct-axis of the utility voltage calculated from a three-phase PLL circuit with reducing $V_{q}$ to zero. When $i_{q r}$ is set to zero $\left(Q_{r}=0\right)$, the utility-side converter works at unity power factor (UPF) as shown in Figure 9 where the current $I_{i}$ and voltage $V_{i}$ are inphase. If $i_{\text {qr }}$ is set to a positive value (positive $Q_{r}$ ), the utility-side converter works at lag PF and absorbs reactive power as shown in Figure 10. When $\mathrm{i}_{\mathrm{qr}}$ is set to a negative value (negative $Q_{r}$ ), it corresponds to a leading PF operation as shown in Figure 11 and in this case it supplies reactive power to the utility. At any time, the reactive power of the utility is given as:

$$
Q_{u}=Q_{L}-Q_{i}
$$

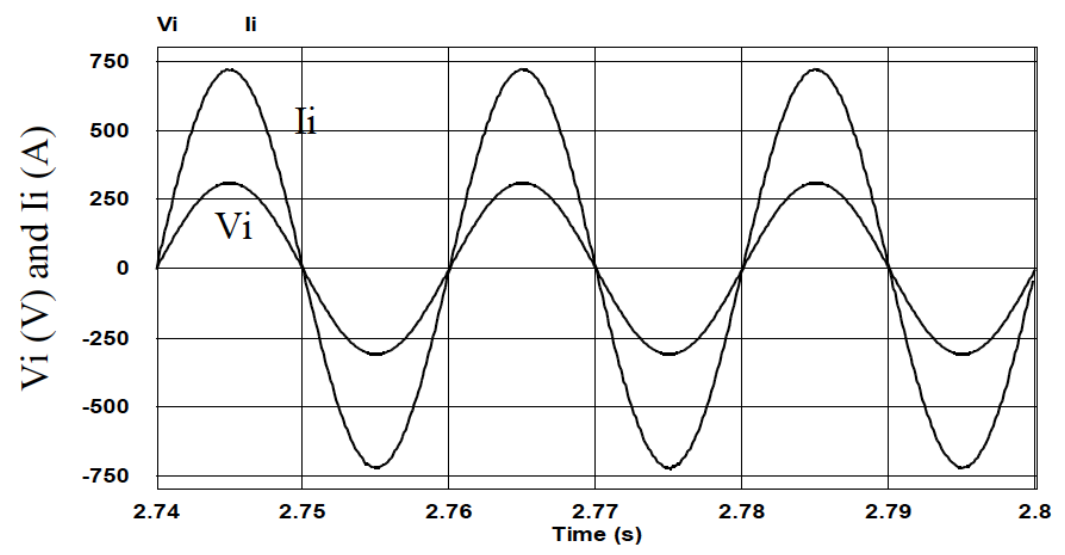

Figure 9: Utility-side converter voltage and current at UPF operation.

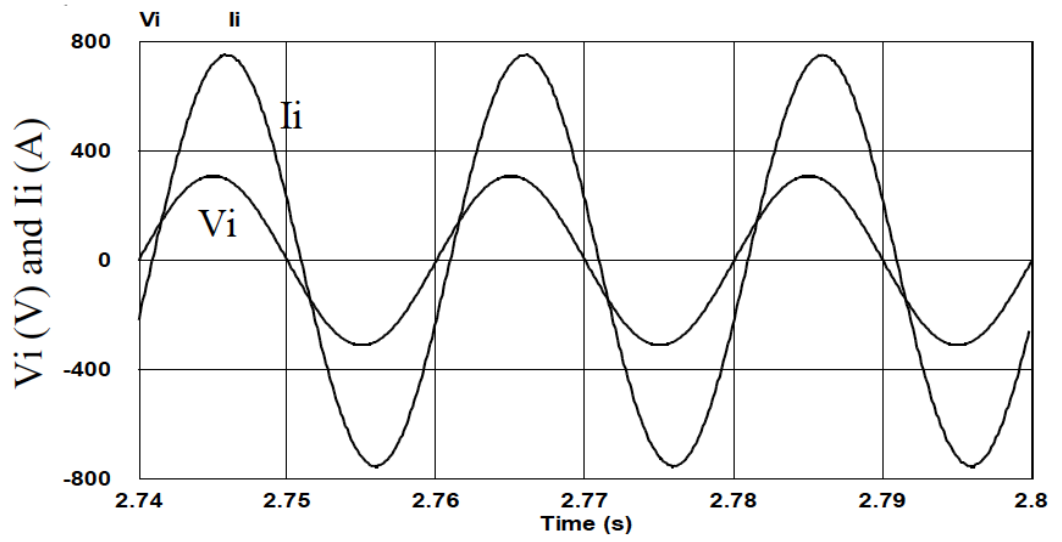

Figure 10: Utility-side converter voltage and current at lag PF operation. 


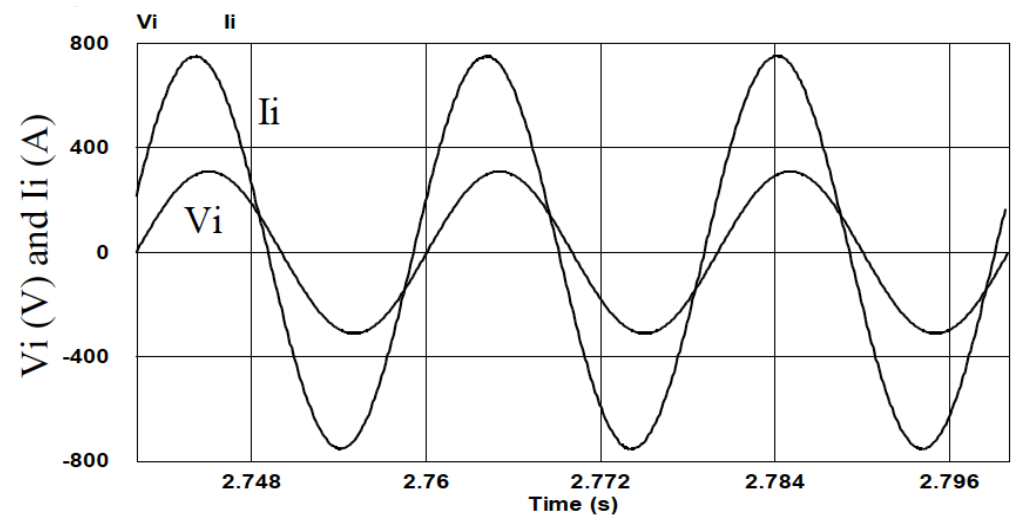

Figure 11: Utility-side converter voltage and current at lead PF operation.

Table 3: Reactive Powers of Load, Utility-Side Converter and Utility at Rated Speed

\begin{tabular}{|c|c|c|c|}
\hline PF & $\mathbf{Q}_{\mathbf{L}}(\mathbf{k V a r})$ & $\mathbf{Q}_{\mathbf{i}}(\mathbf{k V a r})$ & $\mathbf{Q}_{\mathbf{u}}(\mathbf{k V a r})$ \\
\hline \hline UPF & 101.93 & 9.10 & 92.79 \\
\hline Lead PF & 101.93 & 109.15 & -7.22 \\
\hline Lag PF & 101.93 & -90.77 & 192.71 \\
\hline
\end{tabular}

where $Q_{L}$ and $Q_{i}$ are the reactive powers of the load and utility-side converter.

A summery for the reactive power during different PF operations are listed in Table 3 for the micro-grid and utility interactions.

\section{CONCLUSIONS}

A simulation model of the $300 \mathrm{~kW}$ wind turbine, located at Hurghada, Red sea, Egypt, is investigated in a micro-grid with a photovoltaic module of $40 \mathrm{~kW}$ and a wind turbine of $300 \mathrm{~kW}$ for studying the flow of active and reactive power during extreme gust wind scenarios. The simulated wind turbine is equipped with squirrel-cage induction generator and a generator-side converter. This converter is controlled by field-oriented control to capture maximum power available in the wind to follow the MPPT regime. The extreme operating gust variations are simulated based on different pre-gust wind speeds of $9 \mathrm{~m} / \mathrm{s}$, which is the average wind speed of Hurghada city and of $12 \mathrm{~m} / \mathrm{s}$, which is the rated speed of the studied $300 \mathrm{~kW}$ wind turbine to study the power fluctuations at different gusts. The utility-side converter is responsible for controlling the DC bus voltage during transient and steady state operations by applying the $\mathrm{i}_{\mathrm{d}}-\mathrm{i}_{\mathrm{q}}$ current control. The robustness of the power electronics converter is validated under the extreme gust wind conditions and the converters are found to be robust against wind speed variations. The $\mathrm{i}_{\mathrm{d}}-\mathrm{i}_{\mathrm{q}}$ with the hysteresis band current controls generate three-phase currents almost free of harmonics with a simple LC filter. In addition to, the power factor of the utility-side converter can be controlled to adapt with the utility requirements. The showed results emphasize on the capability of the adopted control methods to keep the micro-gird stable even in the extreme gust wind conditions as well as the power flow interaction between the micro-grid and utility.

\section{REFERENCES}

[1] International Energy agency report. Key issues in developing renewables 1997.

[2] El-Tamaly HH, El-Tamaly AM, El-Baset Mohammed AA. Design and control strategy of utility interfaced PV/WTG hybrid system. $9^{\text {th }}$ International Middle East Power System Conference, Shebin El-Kom, Dec. 16-18 2003; 2: 674-699.

[3] Eid A. Stand-alone DC micro-grids: analysis and control. The Second International Conference on Engineering and Applied Science, Tokyo, Japan, March 15-17, 2013; 2191 2198.

[4] Eid A. Performance of grid-connected hybrid photovoltaic/fuel cell/battery distributed generation system. The International Conference on Electrical Engineering and Computer Sciences, Tokyo, Japan, March 15-17, 2013; 147154.

[5] Teixeira L, Zhang Y, Kang Y. Stability analysis of power system in Cape Verde with wind power under wind gust and short circuit fault. 4th International Conference on Electric Utility Deregulation and Restructuring and Power Technologies, Weihai, Shandong, Jul. 6-9, 2011; 1072-1075.

[6] Ministry of electricity and energy-New and Renewable Energy Authority (NREA)-Annual Report 2011/2012. <http://www.nrea.gov.eg>.

[7] Heydari M, Varjani AY, Mohamadian M. A novel variablespeed wind energy system using induction generator and six- 
switch AC/AC converter. 3rd International Conference of Power Electronics and Drive Systems Technology, Tehran, Feb. 15-16, 2012; 244-250.

[8] Wu B, Lang Y, Zargari N, Kouro S. Power conversion and control of wind energy systems. John Wiley \& Sons Inc. and IEEE Press, Jul. 2011.

[9] Cheng PW, Bierbooms WM. Extreme gust loading for wind turbines during operation. J Sol Energy Eng 2001; 123(4): 356-363.

http://dx.doi.org/10.1115/1.1413218

[10] Noureldeen O, Rashad A. Modeling and investigation of gulf El-Zayt wind farm for stability studying during extreme gust wind occurrence. Ain Shams Eng J 2014; 5(1): 137-148. http://dx.doi.org/10.1016/j.asej.2013.09.011

[11] Zeng SC, Xu YX. Research on nonlinear dynamic characteristics of large-scale wind turbine blade in flow fields.
World Automation Congress (WAC), Puerto Vallarta, Jun. 2428, 2012; 1-3.

[12] Roy S. Power output by active pitch-regulated wind turbine in presence of short duration wind variations. IEEE Trans. Energy Conversion, Dec. 2013; 28(4): 1018-1025. http://dx.doi.org/10.1109/TEC.2013.2282992

[13] Masters GM. Renewable and efficient electric power systems. John Wiley \& Sons, Inc., 2004. http://dx.doi.org/10.1002/0471668826

[14] Ganti VC, Singh B, Aggarwal SK, Kandpal TC. DFIG-based wind power conversion with grid power leveling for reduced gusts. IEEE Trans Sustainable Energy 2012; 3(1): 12-20.

[15] Eid A. Control of hybrid energy systems micro-grid. IEEE International Conference on Smart Energy Grid Engineering, Oshawa, Canada, 28-30 Aug. 2013; 1-6. 